Preface

\title{
Editorial Compilation I
}

\author{
Emmanuel J. Favaloro, PhD, FFSC (RCPA) ${ }^{1}$ Giuseppe Lippi, MD ${ }^{2}$ \\ ${ }^{1}$ Department of Haematology, Institute of Clinical Pathology and \\ Medical Research (ICPMR), Westmead Hospital, Westmead, Australia \\ ${ }^{2}$ Section of Clinical Biochemistry, University of Verona, Verona, Italy \\ Semin Thromb Hemost 2016;42:5-8.
}

Welcome to another issue of Seminars in Thrombosis and Hemostasis (STH). This is an inaugural issue published under the "banner" of "editorial compilation." Although STH is primarily a theme-driven publication, the occasional opportunity arises to publish intermittent issues containing more wide-ranging articles of current interest and controversy that do not quite match a current-themed issue in progress. In addition, we also need a vehicle for publishing the contributions from our Eberhard F. Mammen Young Investigator Award winners where these also do not fit within a Theme issue of STH in progress. ${ }^{1-5}$ In previous years, we used the "editorial banner" of "hot topics" to share such interesting potpourri of material with our readership. ${ }^{6-12}$ That series has served us well, and has been very popular with the STH readership. ${ }^{1-3,13-16}$ The new series of "editorial compilation" hopes to continue this tradition, as well as to potentially expand the content more broadly to include the best of unsolicited content as submitted to the journal and after subsequent expert peer review.

This issue begins with the contributions from three of the recent past (2014) Eberhard F Mammen Young Investigator Award winners. The first, from Tersteeg et al, has Coen Maas (a 2014 Young Investigator Award winner ${ }^{4}$ ) as corresponding author, and discusses the alternatives to ADAMTS13 (a disintegrin and metalloproteinase with a thrombospondin type I motif, member 13) to keep von Willebrand factor (VWF) "under control." ${ }^{17}$ VWF is one of the most important proteins of the hemostatic system. Its multimeric state is essential for the natural function to guide platelets to sites of injury. ${ }^{18}$ ADAMTS13 is the key protease that regulates the multimeric state of VWF. Without ADAMTS13, VWF multimers can grow to pathologically large sizes, a well-established risk factor for the life-threatening condition thrombotic thrombocytopenic purpura (TTP). In this situation, VWF-rich thrombi may act to occlude the microvasculature of various tissues. Intriguingly, a complete ADAMTS13 deficiency does not cause continuous TTP, either in patients or genetically targeted mice. Instead, TTP occurs in episodes of disease, separated by extended periods of remission. This indicates that other regulating factors (beyond ADAMTS13) are likely involved in controlling VWF size, and thus influencing the pathological cascade of events in TTP. So, what really happens when ADAMTS13 is (temporarily) unavailable? In this review, the authors explore the possible role of complementary mechanisms that are capable of modifying the thrombogenic potential of VWF.

The second contribution, from Kumar et al is on the changing paradigm of hemophilia management, and focuses on the current available and emerging extended half-life factor concentrates as well as gene therapy. ${ }^{19} \mathrm{Dr}$ Kumar was also a 2014 Young Investigator Award winner. ${ }^{4}$ Management of hemophilia has evolved significantly in the last century-from recognition of the causative mechanism in the 1950s-to commercially available clotting factor concentrates in the 1960s. Availability of lyophilized concentrates in the 1970s set the stage for home-based therapy, followed by introduction of virally attenuated plasma-derived and then recombinant factor concentrates in the 1990s. The same decade also saw the widespread implementation of a paradigm shift in treatment goals from on-demand therapy to prophylactic factor replacement: starting at an early age, to prevent hemarthrosis and subsequent sequelae; this has now become the standard of care for patients with severe hemophilia. In the developed world, the increasing use of homebased prophylactic regimens has significantly improved the quality-of-life and life expectancy of patients with severe hemophilia. Seminal developments in the last 5 years, including the commercial availability of extended half-life factor concentrates and the publication of successful results of gene therapy for patients with hemophilia B, promise to further revolutionize hemophilia care over the next few decades. In this review, the authors summarize the evolution of management for hemophilia, with a focus on extended half-life factor concentrates and gene therapy.
Address for correspondence Emmanuel J. Favaloro, PhD, FFSc (RCPA), Department of Haematology, Institute of Clinical Pathology and Medical Research (ICPMR), Westmead Hospital, Westmead, Australia (e-mail: emmanuel. favaloro@health.nsw.gov.au).
Issue Theme Editorial

Compilation I; Guest Editors: Emmanuel J. Favaloro, PhD, FFSc (RCPA), and Giuseppe Lippi, MD.
Copyright @ $\odot 2016$ by Thieme Medical Publishers, Inc., 333 Seventh Avenue, New York, NY 10001, USA. Tel: +1(212) 584-4662.
DOI http://dx.doi.org/ $10.1055 / \mathrm{s}-0035-1568873$. ISSN 0094-6176. 
The third contribution is also form a 2014 Young Investigator Award winner, Dr Mancuso, and her colleague Dr Fasulo, ${ }^{4}$ and is also related to hemophilia, but this time on the thrombin generation assay (TGA) as a laboratory tool to monitor bypass therapy in patients with hemophilia and inhibitors. $^{20}$ As partly covered in the preceding article, ${ }^{19}$ hemophilia treatment relies upon replacement of the deficient factor to restore physiological levels in plasma. The main complication of replacement therapy is the development of inhibitors to the replacement factor, rendering replacement therapy ineffective and requiring the use of alternative hemostatic drugs known as bypassing agents. The hemostatic response to bypassing agents is different from patient to patient, but also in the same patient during different bleeding episodes. Routine laboratory tests have serious limitations for monitoring efficacy and safety of these bypassing agents. The unpredictable clinical response to bypass therapy and the lack of a monitoring laboratory tool renders surgery in inhibitor patients a huge challenge, both for risk of bleeding and thromboembolic complications. The TGA has been proposed as an effective monitoring tool in this patient population on the basis of results obtained both in vitro and ex vivo. This review aims to summarize the current published evidence on the use of TGA as a laboratory-monitoring tool in patients with hemophilia complicated by inhibitors.

The next article in this issue of STH continues discussion around bleeding disorders, this time in those carrying a deficiency of, or defect in, VWF, and, namely, those with von Willebrand disease (VWD). Franchini et al from the Italian Association of Haemophilia Centres (AICE) describe their study looking into cancers in patients with VWD. ${ }^{21}$ Besides its essential role in hemostasis, ${ }^{18}$ there is growing evidence that VWF has an additional and possibly pleiotropic antitumor effect. To elucidate the clinical significance of this biological activity, the authors conducted a retrospective study on cancers among Italian patients with VWD, using a questionnaire to collect their demographic, clinical, and treatment data. Of the 54 Italian haemophilia treatment centres (HTCs) members of AICE receiving the study questionnaire, 18 (33\%) provided information on 92 VWD patients (61 alive and 31 expired) with 106 cancers, as collected during the period 1981 to 2014 . Of these, 19 (18\%) were hematological malignancies and 87 (82\%) were solid cancers. A discrepancy was observed in terms of the VWD types reflected in the cancer data compared with patients with VWD: $61 \%$ of cancer patients had type $1,36 \%$ type 2 (12\% type $2 \mathrm{~A}, 14 \%$ type $2 \mathrm{~B}, 9 \%$ type $2 \mathrm{M}$, and $1 \%$ type $2 \mathrm{~N}$ ) and $3 \%$ type 3 VWD; in contrast, $79 \%$ of the whole VWD population had type $1,16 \%$ type 2 ( $8 \%$ type $2 \mathrm{~A}, 4 \%$ type $2 \mathrm{~B}, 2 \%$ type $2 \mathrm{M}, 2 \%$ type $2 \mathrm{~N}$ ), and 5\% type 3 (type 2 vs. non-type 2: $p<0.001$ ). Overall, VWD patients with cancer underwent 52 invasive and 72 surgical procedures, were treated with $\mathrm{VWF} /$ factor (F) VIII concentrates in 77 cases, with desmopressin (DDAVP) alone in 24 cases and with DDAVP and VWF/FVIII concentrates in 7 cases, respectively. Hemorrhagic complications were observed only rarely ( $2 \%$ of invasive procedures and radiotherapy and $6 \%$ of surgical interventions). Overall, this report identifies that a substantial number of cancers are recorded among VWD patients and that these patients are safely managed by HTC centers.

This issue then switches to thrombosis, prevention of thrombosis, and bleeding risk, under several situations. First, Riva et al report a systematic review and meta-analysis of major bleeding and case fatality rate with the direct oral anticoagulants (DOACs) in orthopedic surgery. ${ }^{22}$ The DOACs have been proposed as alternatives to low-molecular-weight heparins (LMWHs) for prevention of venous thromboembolism (VTE) in orthopedic surgery. However, the clinical impact of postsurgical bleeding with the DOACs has not been extensively evaluated. The authors therefore searched MEDLINE and EMBASE databases, supplemented with conference abstract books and www.clinicaltrial.gov, including phases II and III randomized controlled trials, comparing the DOACs with LMWHs in patients undergoing major orthopedic surgery. Data regarding major, fatal, and intracranial bleeding were collected, to calculate the pooled relative risk (RR) and the case-fatality rate (CFR), with $95 \%$ confidence interval (CI). The authors retrieved 25 studies (5 evaluating dabigatran, 4 apixaban, 6 edoxaban, and 10 rivaroxaban), totaling 42,170 patients. There was no significant difference between DOACs and LMWHs in the risk of major (1.23 vs. $1.16 \%$; RR: $1.07,95 \%$ CI: $0.89-1.29)$, fatal (0.02 vs. $0.01 \%$; RR: $1.63,95 \% \mathrm{CI}: 0.39$ 6.77), and intracranial bleeding ( 0 vs. $0.01 \%$; RR: $0.33,95 \% \mathrm{CI}$ : 0.03-3.18). The weighted mean CFR of major bleeding was $3.3 \%$ (95\% CI: $1.5-5.7$ ) and 2.3\% (95\% CI: 0.7-4.6), respectively. The authors concluded that bleeding complications and the associated CFR during prophylactic anticoagulation in orthopedic surgery were very low and not significantly different between DOACs and LMWHs.

Next, Burchall et $\mathrm{al}^{23}$ report on a comprehensive assessment of the hemostatic system in polycystic ovarian syndrome (PCOS), which affects 12 to $19 \%$ of women, and has reproductive and metabolic features (endothelial dysfunction, increased diabetes, and cardiovascular risk factors). Patients with PCOS also appear to have altered coagulation and fibrinolysis, with a prothrombotic state and epidemiological evidence of increased risk of VTE. The authors assessed plasminogen activator inhibitor 1 (PAI-1), asymmetric dimethylarginine (ADMA), hormonal and metabolic markers, prothrombin fragments 1 and 2 (PF1 and 2), plasminogen, tissue plasminogen activator (tPA), and thrombin generation (TG), in an established case-control cohort of lean, overweight, and obese women with $(n=107)$ and without PCOS $(n=67)$. Higher levels of ADMA, PAI-1, and plasminogen were seen in PCOS cases, and persisted after adjustment for age and body mass index. PF1 and 2 was marginally lower, while tPA and TG were not different between groups, after adjustment for age and body mass index (BMI). Significant relationships were also observed between hormonal and metabolic factors with ADMA and PAI-1. The authors conclude by hypothesizing that the impaired fibrinolysis they observed in PCOS cases may underpin an increased risk of cardiovascular disease and VTE in PCOS, in the context of abnormal endothelial function and known hormonal and metabolic abnormalities in these patients.

The theme of thrombosis risk continues with the contribution from the guest editors for this issue of the journal, 
Lippi and Favaloro, who attempt to address the question of whether the association between allergy and VTE is casual or causative. ${ }^{24}$ Allergic diseases are very frequent conditions that affect many people worldwide, and whose frequency is constantly increasing. The pathogenesis of allergic reactions and VTE shares several risk factors and predisposing conditions. In particular, the concentration of immunoglobulin $\mathrm{E}$ (IgE) is considerably increased in patients with allergic diseases, and this immunoglobulin exert many prothrombotic and antifibrinolytic activities, especially through interaction with mast cells. In this narrative review, an overview of the current scientific evidence supporting a potential relationship between allergy and the risk of VTE is provided. Although no prospective studies have been published to date, the evidence provided by six large cross-sectional studies and several case reports support the existence of an epidemiological association between different allergic diseases (especially atopy, asthma and celiac disease) and VTE. Two additional investigations reported that the concentration of IgE might predict the onset of severe complications of pulmonary embolism, such as pulmonary infarction and pleural fluid accumulation. These links pave the way to future investigations aimed at establishing whether prevention or treatment of chronic allergic diseases might ultimately be effective to lower the risk of VTE.

Turning to "thrombosis risk" and laboratory testing, Berroëta et al report on the diagnostic performance of a new rapid lateral flow immunoassay in patients suspected of heparin-induced thrombocytopenia (HIT) and its clinical consequences. ${ }^{25}$ The authors prospectively evaluated the diagnostic accuracy of this assay (STic Expert HIT, Diagnostica Stago, Asnières sur Seine, France) alone or in combination with a clinical score in 90 HIT suspected patients. The "4Ts" score was calculated, and enzyme-linked immunoassay (ELISA)-based and serotonin-release assay (SRA) assays for HIT were also performed. The average comparative time taken for tests results were 2 and 5 days for ELISA and SRA, respectively, whereas the STic test could be performed to enable results to be available in 1 hour. In the first part of the study, STic results were not communicated to the clinicians so as to not influence management, and thus properly evaluate its diagnostic performance, alone and in combination with 4Ts score. HIT was diagnosed in 19 patients. The sensitivity, specificity, positive, and negative predictive values for the STic test alone were $95,92,75$, and $98 \%$, respectively, with an accuracy of $92 \%$. The likelihood ratios for positive and negative results with the STic test were 11.2 and 0.06 , respectively. The combination of the "4Ts" score and the STic test results had a negative predictive value of $100 \%$ and a negative likelihood ratio of 0 . The authors concluded that the favorable performance of the STic test may allow for the rapid exclusion of HIT in combination with a low-to-intermediate pretest clinical probability. During the subsequent year, a second study used the STic test in real time to rapidly exclude HIT diagnosis, and the authors observed a 50\% reduction in danaparoid administration in HIT-suspected patients.

Laboratory testing is also a part focus of the two remaining articles of this issue of the journal. Franchini et al first assess the correlation between $\mathrm{ABO}$ blood group, and conventional hematological and metabolic parameters in blood donors. ${ }^{26}$ Although several studies have investigated and confirmed the existence of an association between $A B O$ blood type and several human disorders, especially cardiovascular disease and cancer, little is known on the physiological influence or association of ABO blood groups on the basal levels of certain conventional hematological and metabolic parameters. The authors evaluated samples from a total of 7,723 consecutive healthy blood donors for alanine aminotransferase, aspartate aminotransferase, gamma-glutamyl transferase, total bilirubin, total cholesterol, high-density lipoprotein cholesterol (HDL-c), lowdensity lipoprotein cholesterol, triglycerides, creatinine, iron, ferritin, uric acid, glucose, hemoglobin, and platelet count, as well as ABO typing. The most relevant finding was the identification of significantly higher values of total cholesterol and HDL-c in subjects with blood group A compared with those with $O$ blood type, with the highest levels being observed in A1 subtype. The authors conclude by highlighting the positive association between A blood type and plasma lipid levels, which they believe supports its potential role in the pathogenesis of atherosclerosis and the clinical observations of increased vulnerability to cardiovascular disease of individuals with non-O blood groups.

Finally, Shou et al report on an assessment of biological variation for lupus anticoagulant (LA), antithrombin (AT), protein $\mathrm{C}$ (PC), protein S (PS), and VWF assays. ${ }^{27}$ These assays are important in diagnosis and therapeutic monitoring of thrombosis and hemostasis diseases, but thus far, no published study has focused on the biological variations in LA testing, and only a few studies have examined the biological variations of AT, PC, PS, and VWF:Ag. With the latest fully automated instruments and improved reagents, the analytical, within-subject and between-subject biological variations were estimated for these five coagulant parameters in a cohort of 25 apparently healthy subjects. Blood specimens were collected at 8:00 AM, 12:00 PM, and 4:00 PM on days 1, 3, and 5 . The analytical variation $\left(\mathrm{CV}_{\mathrm{A}}\right)$ values of all the parameters were less than $3 \%$. The within-subject variation $\left(\mathrm{CV}_{\mathrm{W}}\right)$ and between-subject variation $\left(\mathrm{CV}_{\mathrm{G}}\right)$ values of the $\mathrm{LA}$ normalized ratio were 4.64 and $6.83 \%$, respectively. No significant differences were observed in the intraday and interday biological variations of LA tests, or in AT, PC, PS, and VWF: $\mathrm{Ag}$ values. In addition, the utility of the conventional population-based reference intervals of the five coagulation parameters was evaluated by the index of individuality, and data on $\mathrm{CV}_{\mathrm{W}}$ and $\mathrm{CV}_{\mathrm{A}}$ were used to calculate the reference change value to identify the significance of changes in serial results from the same individual.

As always, we would like to thank all the authors to this issue of STH for their original and comprehensive contributions. We also hope that you, representing the readership of this journal, find this inaugural issue of "editorial compilations" of substantial interest. This will of course be determined in time, as measured and established for previous issues of this journal. ${ }^{1-3,13-16}$ 


\section{References}

1 Favaloro EJ. 2011 Eberhard F. Mammen award announcements. Semin Thromb Hemost 2011;37(5):431-439

2 Favaloro EJ. 2012 Eberhard F. Mammen award announcements. Semin Thromb Hemost 2012;38(5):425-432

3 Favaloro EJ. 2013 Eberhard F. Mammen award announcements. Semin Thromb Hemost 2013;39(6):567-574

4 Favaloro EJ. 2014 Eberhard F. Mammen award announcements: part II-Young Investigator Awards. Semin Thromb Hemost 2014; 40(7):718-723

5 Favaloro EJ. 2015 Eberhard F Mammen award announcements: Part II-Young Investigator Awards. Semin Thromb Hemost 2015; 41(8):809-815

6 Favaloro EJ. Hot topics I: A Potpourri of Current Issues and Controversies in Thrombosis and Hemostasis. Semin Thromb Hemost 2007;33(8):723-726

7 Favaloro EJ. Hot topics II: an editorial collection of current issues and controversies in thrombosis and hemostasis. Semin Thromb Hemost 2008;34(1):3-6

8 Favaloro EJ. Hot topics III. Preface. Semin Thromb Hemost 2012; 38(1):1-4

9 Favaloro EJ. Hot Topics IV. Semin Thromb Hemost 2013;39(1):1-4

10 Favaloro EJ. Hot topics V. Preface. Semin Thromb Hemost 2014; 40(1):5-10

11 Favaloro EJ. Hot topics VI. Preface. Semin Thromb Hemost 2014; 40(7):713-717

12 Favaloro EJ. Hot Topics VII. Semin Thromb Hemost 2015;41(4): 355-358

13 Favaloro EJ. Editorial. Winners of the Inaugural Eberhard F. Mammen Award for Most Popular Article. Semin Thromb Hemost 2009; 35:587-590

14 Favaloro EJ. Winners of the 2010 Eberhard F. Mammen award for most popular article during 2008-2009. Semin Thromb Hemost 2010;36(7):685-692

15 Favaloro EJ. 2014 Eberhard F. Mammen award announcements: Part I - most popular articles. Semin Thromb Hemost 2014;40(4): 407-412

16 Favaloro EJ. 2015 Eberhard F. Mammen Award Announcements: Part I-Most Popular Articles. Semin Thromb Hemost 2015;41(7):673-679
17 Tersteeg C, Fijnheer R, Deforche L, et al. Keeping von Willebrand factor under control: Alternatives for ADAMTS13. Semin Thromb Hemost 2016;42(1):9-17

18 Yee A, Kretz CA. Von Willebrand factor: form for function. Semin Thromb Hemost 2014;40(1):17-27

19 Kumar R, Dunn A, Carcao M. Changing paradigm of hemophilia management: extended half-life factor concentrates and gene therapy. Semin Thromb Hemost 2016;42(1):18-29

20 Mancuso ME, Fasulo MR. Thrombin generation assay as a laboratory monitoring tool during bypassing therapy in patients with hemophilia and inhibitors. Semin Thromb Hemost 2016;42(1): 30-35

21 Franchini M, Di Perna C, Santoro C, et al; On Behalf of the Italian Association of Haemophilia Centres. Cancers in patients with von Willebrand disease: a survey from the Italian Association of Haemophilia Centres. Semin Thromb Hemost 2016;42(1): 36-41

22 Riva N, Dentali F, Permunian ET, Ageno W. Major bleeding and case fatality rate with the direct oral anticoagulants in orthopaedic surgery: a systematic review and meta-analysis. Semin Thromb Hemost 2016;42(1):42-54

23 Burchall GF, Piva TJ, Linden MD, Gibson-Helm ME, Ranasinha S, Teede HJ. Comprehensive assessment of the haemostatic system in polycystic ovarian syndrome. Semin Thromb Hemost 2016;42(1): 55-62

24 Lippi G, Favaloro EJ. Allergy and venous thromboembolism: A casual or causative association? Semin Thromb Hemost 2016; 42(1):63-68

25 Berroëta C, Crespin M, Bouabdallah K, et al. Diagnostic performance of a new rapid lateral flow immunoassay in patients suspected of heparin-induced thrombocytopenia and its clinical consequences. Semin Thromb Hemost 2016;42(1):69-74

26 Franchini M, Mengoli C, Capuzzo E, Terenziani I, Bonfanti C, Lippi G. Correlation between $\mathrm{ABO}$ blood group, and conventional hematological and metabolic parameters in blood donors. Semin Thromb Hemost 2016;42(1):75-86

27 Shou W, Chen Q Wu W, Cui W. Biological variations of lupus anticoagulant, antithrombin, protein C, protein $S$ and VWF assays. Semin Thromb Hemost 2016;42(1):87-92 